\title{
O PÊNDULO OSCILANTE sociologia do trabalho e movimento sindical no Brasil ${ }^{1}$
}

\author{
Marco Aurélio Santana* \\ Ruy Braga*
}

\begin{abstract}
O presente artigo analisa a relação estabelecida entre a sociologia do trabalho e o sindicalismo no Brasil. Isso é feito cobrindo-se três momentos dessa relação. Tendo como pano de fundo as sucessivas conjunturas políticas e econômicas, partimos daquela primeira geração de sociólogos do trabalho até o período recente, buscando identificar os pontos mais característicos dessa trajetória. Trabalhamos com a hipótese segundo a qual, ao longo de sua trajetória, a sociologia do trabalho no Brasil foi marcada, em seus primórdios, pela busca de afirmação e profissionalização (1950/1960); posteriormente, desenvolveu um forte engajamento político-social, assumindo um caráter público e servindo para conformar certas identidades sociais (1970/1980); por fim, teria derivado para uma sociologia para as políticas públicas (1990/2000).

PALAVRAS-CHAVE: sociologia do trabalho, identidades sociais, trabalhadores, sindicalismo.
\end{abstract}

\section{SOCIOLOGIA DO TRABALHOE PROFISSIONALIZAÇÃO}

Na apresentação que fez do livro de Juarez Rubens Brandão Lopes, A crise do Brasil arcaico (1967), notável estudo inspirado em Weber sobre a prática das relações de trabalho brasileiras no final da década de 1950, a partir de indústrias têxteis em dois municípios localizados no Estado de Minas Gerais, Leôncio Martins Rodrigues observou:

O mérito maior dessa publicação - que aproveita as melhores contribuições da moderna Sociologia Industrial - consiste, a nosso ver, em ter posto de lado as considerações normativas e ideológicas que habitualmente se infiltram nos escritos referentes à classe operária (Rodrigues, 1967).

Sabemos que, no decorrer do período de

\footnotetext{
Doutor em Sociologia. Professor do Programa de PósGraduação em Sociologia e Antropologia da Universidade Federal do Rio de Janeiro - UFRJ.

Largo de S. Francisco, 1 - Sala 420. Centro. Cep: 20051070. Rio de Janeiro - RJ - Brasil. msantana@ifcs.ufrj.br

** Doutor em Ciências Sociais. Professor do Programa de Pós-Graduação em Sociologia da Universidade de São Paulo - USP. ruy.braga@uol.com.br

${ }^{1} \mathrm{O}$ presente artigo é uma versão revista e ampliada do artigo publicado em Work \& Occupations, n. 36, 2009
}

profissionalização das ciências sociais no Brasil, especialmente a partir do início dos anos 1960, as visões totalizantes de nossa realidade social foram, até certo ponto, secundarizadas pelos estudos que sucederam as obras seminais de Sérgio Buarque, Raymundo Faoro e Gilberto Freyre. A profissionalização do campo sociológico brasileiro priorizou trabalhos mais voltados para o esclarecimento sistemático de aspectos até então não suficientemente estudados de nossa formação histórica. Representativa desse momento, a observação de Leôncio Martins Rodrigues sintetiza uma preocupação permanente da sociologia do trabalho desse período: diferenciar-se dos estudos "militantes" sobre os trabalhadores brasileiros - especialmente, daqueles oriundos do Partido Comunista Brasileiro (PCB) -, para ser capaz de consolidar um campo reflexivo fundamentalmente orientado pela sociologia profissional acadêmica.

No contexto da profissionalização de sua prática, a sociologia do trabalho, nos anos 1960, ocupou-se principalmente da formação de uma "nova" classe operária surgida durante a urbanização, industrialização e modernização acelerada da 
sociedade brasileira. O processo de industrialização dirigido pelo Estado "populista", ${ }^{2}$ nos anos 1950, redefiniu a estrutura de classes do país, reestruturando as instituições políticas oligárquicas dominadas pelas antigas aristocracias rurais e consolidando o advento de um novo proletariado de origem rural: massa urbana recém-chegada do campo, vivendo nas periferias dos centros urbanos industriais e sem vínculos simbólicos, políticos ou organizativos com a antiga classe operária formada no início do século XX.

Não era de se estranhar, portanto, que a relação entre as massas operárias e o Estado "populista" estivesse no centro das preocupações dessa nascente sociologia profissional do trabalho. Ao menos duas vertentes interpretativas se consolidaram naquele período: em primeiro lugar, surgiram estudos que buscavam investigar a relação dos trabalhadores com os sindicatos por meio da problematização das origens culturais e regionais da classe operária (Lopes, 1964; Rodrigues, 1970). Em seguida, vieram as investigações dedicadas à relação entre o sindicalismo e o Estado populista na formação da consciência de classe (Simão, 1966; Rodrigues, 1968).

De acordo com Vianna (1986a), esses estudos, que praticamente inauguraram a sociologia profissional do trabalho no Brasil, já eram marcados pela concepção de que, antes de 1930, o proletariado industrial, formado majoritariamente por imigrantes e orientado pela ideologia anarquista, havia conseguido garantir sua autonomia, espontaneidade e ímpeto de luta, mas que, em contrapartida, no pós-1930, com a constituição de um novo proletariado de origem rural, portador de certa passividade política e sem contato com ideologias anticapitalistas, a classe operária teria se tornado uma presa fácil das manipulações desse Estado "populista”.

${ }^{2}$ Uma das principais características do fenômeno populista é o tipo de vínculo "carismático" estabelecido entre as massas urbanas e o líder político. Esse fato supõe a utilização de um diversificado sistema de técnicas políticas utilizadas para construir o consentimento das classes trabalhadoras ao projeto político populista, além de garantir a adesão das classes médias urbanas (Ianni, 1978). Mais recentemente tem-se buscado rediscutir a noção de populismo. Ver, entre outros, Ferreira (2001).

\section{DA SOCIOLOGIA PROFISSIONAL À QUES- TÃO DO TRABALHO NO BRASIL}

Acompanhando a profissionalização das ciências sociais no Brasil, a reflexão desse período adquiriu formas claramente identificadas com as diferentes interpretações da sociedade capitalista industrial moderna: a escola estadunidense das relações industriais (Elton Mayo) e a sociologia do trabalho francesa (Georges Friedmann, Pierre Naville, Alain Touraine...), notadamente (Lopes, 1964; Rodrigues, 1970). O contraste com a geração anterior de estudos baseados nas análises de intelectuais vinculados organicamente aos diferentes partidos políticos operários, sobretudo, ao PCB, tornou-se patente (Miglioli, 1963).

Para os pioneiros da sociologia profissional do trabalho brasileira, tratava-se de uma luta simbólica travada no terreno científico contra as ideologias político-programáticas orientadas por tradições partidárias. Daí o desejo de forte diferenciação verificado em alguns dos mais importantes estudos dessa época. Nas palavras de Guimarães:

Para os pioneiros da construção do campo da Sociologia do Trabalho Industrial, o estudo da realidade social do trabalho era terreno onde se travava uma batalha crucial: a batalha pela construção de um campo de investigações sociológicas sobre o trabalho e os trabalhadores. Ou seja, naquele momento, estava em jogo um desafio - o da legitimação da Sociologia enquanto disciplina, capaz de gerar uma nova abordagem da realidade social (2004, p. 43).

Já em meados dos anos 1970, contudo, as noções de "passividade política" e de ausência de "consciência de classe" do novo proletariado industrial, presentes nas análises sociológicas da década anterior, iriam ser rapidamente substituídas por outras diametralmente opostas: a "radicalidade" e a "combatividade" do "novo sindicalismo". Vejamos... No dia 12 de maio de 1978, os trabalhadores da fábrica de caminhões Saab-Scania, no "ABCD paulista", ${ }^{3}$ decidiram pa-

${ }^{3}$ Zona industrial formada por sete municípios da Região Metropolitana da cidade de São Paulo: Santo André ("A"), São Bernardo do Campo (“B”), São Caetano do Sul (“C”), Diadema ("D”), Mauá, Ribeirão Pires e Rio Grande da Serra. 
rar as máquinas e cruzar os braços. Reivindicando um aumento salarial em torno de $20 \%$, os 2 mil trabalhadores metalúrgicos daquela empresa promoveram o início de uma greve que iria marcar época. A paralisação da Saab-Scania iniciou um intenso movimento grevista que espalharia por toda a região do ABCD paulista e para além dela, com importantes desdobramentos políticos na luta contra a ditadura civil-militar implantada no Brasil pós-1964.

Os movimentos que tiveram lugar no ABCD paulista no final dos anos 1970 inauguraram uma ampla luta contra a superexploração do trabalho e a legislação política repressiva que atrelava o movimento sindical ao Estado e restringia as formas de representação dos trabalhadores. Marcadas pela espontaneidade e por sua radicalidade, tais greves inauguraram o que seria uma nova prática sindical e política. Rejeitando a colaboração, os pactos sociais e o imobilismo que, em seu entendimento, haviam caracterizado boa parte da esquerda brasileira até então, as greves do ABCD criaram um movimento social fundado no confronto social e na independência de classe.

Após o grande ciclo grevista do final dos anos 1970, especialmente com as greves de 1978-1979, a década de 1980 iniciou-se com um claro refluxo da ação sindical. Se, entre 1978 e 1979, o número de trabalhadores em greve saltou de meio milhão para mais de três milhões e duzentos mil, em 1980, contudo, esse número cai para oitocentos mil. A combinação da derrota da grande greve dos " 41 dias" no ABCD paulista, no início de 1980, com a recessão econômica, lançou o movimento sindical na direção do terreno econômico-corporativo, preocupado com a preservação dos empregos e com a garantia do poder aquisitivo dos salários.

A tendência ao declínio das greves somente foi revertida a partir de 1983, com o ressurgimento de um ativismo sindical fortemente engajado no terreno da política e, em grande medida, sustentado pelo sucesso do movimento pelas Eleições Diretas para Presidente da República - também conhecido como movimento pelas “Diretas Já”. Esse movimento agregou diversos setores da sociedade brasileira, tendo tomado parte dele vários partidos políticos de oposição ao regime civil-militar, além de lideranças sindicais, intelectuais, estudantis e jornalísticas, tais como, Luiz Inácio Lula da Silva e Fernando Henrique Cardoso.

Sinteticamente, após algumas manifestações públicas nos Estados de Pernambuco e de Goiás, ocorre um primeiro comício no dia 27 de novembro de 1983, na cidade de São Paulo. Com o crescimento do movimento, que coincidiu com o agravamento da crise econômica - em que coexistiam um processo hiperinflacionário (a taxa de inflação chegou a $239 \%$ no ano de 1983) e uma profunda recessão-, ocorreu um novo ciclo de mobilização dos sindicatos. Em 1984, o movimento sindical reuniu condições para se mobilizar abertamente. Marcado para o dia do aniversário da cidade de São Paulo (25 de janeiro), o primeiro grande comício da campanha por eleições diretas para presidente foi viabilizado por Franco Montoro, então governador paulista, na Praça da Sé. A partir daí, o movimento ganhou as ruas e a mídia.

Mesmo depois da relativa derrota do movimento pelas "Diretas já", ${ }^{4}$ na segunda metade dos anos 1980, o movimento sindical brasileiro viveu um momento de forte ascensão, traduzido pela renovação de seu impulso grevista. Oápice do movimento grevista dos anos 1980 ocorreu em 1988, quando tivemos 63,5 milhões de jornadas de trabalho paradas - um volume superior ao de todos os anos anteriores. A duração das greves foi de, em média, sete dias em 1987 e nove dias em 1988. Essa década assistiu, também, ao ressurgimento das greves gerais, que procuraram assumir uma dimensão nacional: 21 de julho de 1983, 12 de dezembro de 1986, 20 de agosto de 1987 e, coroando essa fase de greves nacionais, 14 e 15 de março de 1989 (ver, para mais detalhes, Noronha, 1992).

4 Durante o mês de abril de 1984, o então presidente-
general João Figueiredo promoveu o conhecido "Pacote de
Abril", aumentando a censura sobre a imprensa e promo-
vendo prisões e aberta violência policial. A "Emenda das
Diretas", batizada com o nome do deputado federal autor
da emenda constitucional, deputado Dante de Oliveira,
foi derrotada na Câmara dos Deputados no dia 25 de abril
de 1984 (para uma detalhada descrição dos acontecimen-
tos, ver Oliveira e Leonelli, 2004). No entanto, o movi-
mento pelas "Diretas Já" teve grande importância na
redemocratização do Brasil. 
Essa última grande greve geral exigiu a reposição das perdas salariais decorrentes das políticas de ajuste inflacionário e objetivou garantir uma política econômica favorável aos interesses dos trabalhadores, tendo atingido cerca de 35 milhões de trabalhadores. Trata-se do movimento grevista de maior envergadura da história das greves gerais do país e da mais importante greve geral dos anos 1980 - que paralisou amplos setores ligados à indústria, transportes, funcionalismo público e serviços em praticamente todas as principais capitais do país (Antunes, 1995).

Além das greves gerais, os anos 1980 presenciaram, também, a eclosão de várias greves com ocupação de fábricas. Em 23 de novembro de 1981, o ciclo grevista com ocupação começa com a greve da Ford em São Bernardo do Campo. Essa foi uma greve muito peculiar, pois alimentada pelo protesto contra a condenação de Lula e de outros importantes sindicalistas cassados pela Lei de Segurança Nacional (Brito, 1989). Em 1985, ocorreu a greve de 28 dias dos operários metalúrgicos da General Motors de São José dos Campos, realizada entre os meses de abril e maio.

Em março de 1989, a região de Contagem, no Estado de Minas Gerais, viveu duas ocupações de fábricas: as greves da Belgo-Mineira e da Mannesmann. A resistência dos trabalhadores à ameaça de desocupação da fábrica pela polícia chegou a ponto de eles cercarem os galpões onde dormiam com arame farpado, tambores de óleo e plástico, ameaçando incendiar as plantas fabris caso houvesse a entrada da Polícia Militar. Situação similar ocorreu em novembro de 1988, quando os metalúrgicos da Companhia Siderúrgica Nacional de Volta Redonda, Estado do Rio de Janeiro, deflagraram sua quarta greve na década de 1980. Ocorreu a ocupação da fábrica por dezesseis dias e a invasão por tropas do exército que reprimiram os operários, deixando atrás de si um saldo de três trabalhadores mortos (Graciolli, 1997).

Sinteticamente, pela importância do ativismo sindical e pelo número de greves, os anos 1980 podem ser considerados a década de ouro do movimento sindical brasileiro. Ao mesmo tem- po em que avançava em seus níveis de mobilização, ganhava também em conformação políticoinstitucional. Será ao longo dessa década que veríamos o sindicalismo brasileiro formando centrais sindicais de corte nacional, que dariam vertebração às suas lutas gerais, como, por exemplo, a Central Única dos Trabalhadores (CUT), em 1983, e a fundação e o crescimento de um partido político de forte marca sindical em sua origem, o Partido dos Trabalhadores (PT), em 1980. Esses dois elementos, inclusive, serviriam de pontos de apoio também para o desenvolvimento do "novo sindicalismo".

Assim, tínhamos um movimento dos trabalhadores em franco ascenso político-institucional, com forte presença no cenário e no debate político mais geral, com amplo poder de mobilização e orientação voltada para à base de trabalhadores das categorias profissionais. Tudo isso se refletiu, como vimos, em um enorme volume de greves. Greves em empresas, greves setoriais, greves nacionais, greves com ocupação de fábricas. Naturalmente, a sociologia do trabalho brasileira não poderia atravessar incólume esse período e rapidamente passou a privilegiar a observação da vida cotidiana das fábricas e a construção subjetiva da experiência do trabalho fabril.

Uma marcante presença do marxismo como principal instrumento teórico de análise - temperado pela recepção dos trabalhos de Harry Braverman e de Edward Palmer Thompson ${ }^{5}$ - pôde ser claramente identificada em praticamente toda a década. Como era de se esperar, o estudo das greves e conflitos sociais mudou seu foco do desempenho das lideranças sindicais, décadas de 1960 e 1970, para a análise da relação entre as reivindicações dos trabalhadores, as condições do processo de trabalho e as práticas sociais inovadoras que emergiam do "chão de fábrica".

Na verdade, esse novo estilo investigativo emergiu caracterizado por uma forte crítica àquelas análises que consideravam a classe trabalhadora brasileira "passiva" e destituída de "consciên-

${ }^{5}$ Acerca da recepção da obra de Thompson no Brasil, incluindo as produções historiográfica e sociológica, ver Mattos(2006). 
cia de classe”. Ao estudarem as práticas sociais dos trabalhadores no chão de fábrica, os novos pesquisadores foram revelando, por meio de seus estudos de caso, grupos de trabalhadores heterogêneos, capazes de desenvolver complexas estratégias de resistência à dominação e à disciplina fabril. Segundo Sader e Paoli,

Os pesquisadores das ciências sociais nos anos 80 se viram diante de um momento político marcado por movimentos vários de luta contra opressões diversas, cujo processo tirava de cena os atributos de 'alienação' e heteronomia tradicionalmente atribuídos aos trabalhadores $(1986,60){ }^{6}$

Por meio da experiência do "novo sindicalismo”, os sociólogos do trabalho brasileiros passaram a encarar o desafio de reconstruir uma interpretação científica acerca das práticas sociais dos trabalhadores, sustentada na recuperação do significado da perspectiva dos múltiplos sujeitos que a construíam. A interlocução da sociologia do trabalho com esses "novos sujeitos políticos" fez com que as relações entre a vida fabril e a vida extrafabril fossem valorizadas, destacando os vínculos entre, de um lado, as práticas e as representações sociais construídas na família, na escola, nos bairros operários e, de outro, o cotidiano produtivo (Lobo; Soares, 1985; Cabanes, 2002).

\section{UMA SOCIOLOGIA PÚBLICA DO TRABALHO}

Como era de se esperar, os sociólogos brasileiros mostraram-se profundamente atraídos pelo caráter inovador das demandas surgidas no contexto das grandes lutas de classes do final dos anos 1970 e, em um momento, marcado pelo avanço dos movimentos populares contra o regime autoritário, ajudaram a construir a identidade desse

\footnotetext{
${ }^{6}$ Partindo aqui de uma linha um tanto esquemática, dirí amos que, onde antes se via a importância do Partido Comunista e de sua organização para os trabalhadores, com certo tom oficial, passou-se a ver as bases sociológicas e suas determinações, que teriam como efeito analítico a ideia de "passividade"; agora, frente ao forte ascenso operário, ia-se em busca do trabalhador "puro", "autônomo", até então“perdido" e "soterrado" nas leituras e práticas que primavam pelo foco nas lideranças, partidos, máquinas sindicais e opressão das empresas.
}

novo sujeito político: o "novo sindicalismo". Uma espécie de vínculo "orgânico" entre estudiosos e sindicalistas foi sendo forjado, legitimando a opinião segundo a qual o "novo sindicalismo" coroou a ação de um grupo social que, embora desfrutando de uma situação salarial relativamente vantajosa, estava igualmente submetido a difíceis condições de trabalho impostas pelas empresas no contexto do regime civil-militar, razão pela qual seria capaz de assumir a vanguarda de um movimento de contestação ao autoritarismo da gestão da força de trabalho.

É perfeitamente possível afirmar que, ao longo dos anos 1970 e 1980, forjou-se uma sociologia pública "orgânica" do trabalho no Brasil, conforme a definição recentemente consagrada por Michael Burawoy (2005). Aliás, não nos esqueçamos de que os conceitos gramscianos de "intelectual orgânico" e de "hegemonia" tornaram-se moeda corrente nesse período, nas fileiras do movimento sindical "combativo", e o próprio Antonio Gramsci foi alçado à curiosa condição de intelectual "semioficial" do PT e da CUT. ${ }^{7}$ Nesses termos, a sociologia do trabalho brasileira, agora "pública e orgânica”, cumpriu com um importante papel na tarefa de garantir e legitimar o juízo segundo o qual o "novo sindicalismo", ao enfrentar conjuntamente as gerências e os militares, articulando a crítica ao autoritarismo fabril à crítica ao autoritarismo estatal, delineava uma autêntica alternativa dos trabalhadores aos dilemas vividos pela transição democrática brasileira.

Além da noção de alternativa dos trabalhadores, outra ideia muito marcante da sociologia pública do trabalho brasileira do período - e que foi central para a consolidação da ideia do "novo sindicalismo" - é a noção de ruptura radical com o passado. Para Francisco Weffort, um dos principais expoentes dessa nova vertente teórica, o golpe de 1964 teria aberto a perspectiva de repensar tanto teórica quanto politicamente a participação da classe trabalhadora na cena política brasileira:

\footnotetext{
${ }^{7}$ Acerca da influência do pensamento de Gramsci no PT, assim como na sociologia e ciência política brasileiras, ver Bianchi (2007).
} 
O período pós-64 representa uma ruptura, ou melhor, oferece as bases para uma ruptura, ao nível das elites intelectuais e políticas, da imagem elitista feita sobre a classe operária. O elitismo veio à tona, o que cria a possibilidade de se formular um ponto de vista novo sobre o que pode vir a ser a participação da classe operária em nossa política (Weffort, 1976, p. 82).

A visão da história marcada pela ruptura radical com o passado, contudo, não significava apenas uma distinção entre partes, mas, em grande medida, veio somada à valorização de uma das partes em que se cindira a história, jogando-se a outra imediatamente para o espaço do negativo, uma espécie de anjo caído do processo. Sintomaticamente, tanto a "velha" sociologia profissional do trabalho quanto a "nova" sociologia orgânica do trabalho elegem o período 1930-64 como o momento da produção do erro da classe operária. Desse modo, as análises realizadas sob essa perspectiva não só passaram ao largo das possíveis continuidades e semelhanças entre os períodos nos quais dividiam a história, como também tiveram dificuldades em perceber suas especificidades.

No caso da constituição do "novo sindicalismo", tanto a ideia da ruptura como a da desqualificação de outros períodos produziram efeitos discursivos e práticos, levando a uma confusão entre o que é e o que deve ser. Se a "velha" sociologia profissional do trabalho partiu da suposta "positividade" de um dos períodos (velha classe trabalhadora imigrante) para tentar entender a "negatividade" do outro (novo proletariado de origem rural, refém do Estado populista), a "nova" sociologia pública do trabalho brasileira partiu da suposta "negatividade" de um dos períodos (sindicalismo "pelego", "colaboracionista"...) para a proposição da "positividade" de outro (o "novo sindicalismo", combativo e autêntico).

Diferentemente, porém, dos estudos da "velha" sociologia profissional do trabalho, alguns estudos da "nova" sociologia pública do trabalho tiveram forte influência sobre o movimento sindical, fornecendo-lhe e com ele adquirindo novas dimensões, em um contexto marcado por redefinições e disputas. A divergência e a disputa de posições nos campos político e sindical leva- ram ao estabelecimento de uma via de mão dupla entre os sindicalistas e o meio acadêmico. Assim, se a identificação das correntes interpretativas com os grupos sindicais envolvidos refletiu simpatias e proximidades com tendências políticas, os acadêmicos contribuíram, com suas análises, igualmente, para reforçar a identidade dos grupos uns em relação aos outros.

É a partir dessa relação que se estabeleceram os marcos centrais que informaram suas visões acerca do passado e do presente, balizando o corte entre o "velho" e o "novo". A consolidação, nos estudos acadêmicos, de uma visão crítica acerca do papel desempenhado pelos militantes do PCB e pelo movimento sindical no período 1945-64 deuse, sobretudo, com os ensaios de Weffort (1973; 1978a), um dos mais vigorosos pilares de sustentação da nova sociologia pública do trabalho. A leitura do passado apresentada pelo autor não estava desarticulada de suas práticas e projetos no presente. Ao longo da década de 1970, Weffort foi ativo participante dos debates travados no campo político sobre a formação de um partido de natureza popular e socialista no Brasil, o que resultou em sua associação ao grupo que se engajou na construção do PT. ${ }^{8}$

A produção acadêmica de Weffort acerca do período anterior a 1964, segundo sua própria intenção, mantém claras relações com a sua inserção e orientação no campo político. Para ele,

... a revisão crítica do passado não se refere apenas ao passado [...] o problema que inevitavelmente se coloca em face das questões do presente de uma esquerda perplexa e desvinculada da classe operária é o da avaliação crítica da heranca recebida.[...] Com que parte da herança devemos ficar? (Weffort, 1978b, p. 17-18).

Em suas reflexões acerca das orientações da classe operária no pré-1964, Weffort (1973; 1978a)

${ }^{8}$ Francisco Weffort é uma figura-chave desse período. Além da qualidade de sua interpretação teórica sobre a sociedade brasileira e latino-americana, especialmente presente em seus estudos sobre o populismo, Weffort foi um destacado dirigente do PT, chegando ao cargo de Secretário-Geral do partido já no início da década de 1980 Imediatamente após a derrota de Luiz Inácio Lula da Silva para Fernando Henrique Cardoso, em 1994, Weffort deixou a secretaria-geral do PT para assumir "transformisticamente" o cargo de Ministro da Cultura do governo de Fernando Henrique Cardoso. 
confere centralidade à prática sindical do PCB, vista como agente fundamental na constituição do que ele chama de "sindicalismo populista". Segundo sua análise, o sindicalismo praticado por aqueles militantes teria sido pautado pelo reformismo nacionalista; pelo controle das massas, com vistas a dar continuidade ao "populismo"; pela centralidade atribuída ao Estado, e não à sociedade civil, como espaço de intervenção; pela orientação dirigida para a atuação nos setores decadentes da economia (indústria tradicional) e junto ao setor público; pela prioridade dada aos objetivos políticos em detrimento dos econômicos. Na visão do autor, sob essa orientação, o sindicalismo do período 1945-64 revelou-se incapaz de assumir o controle da classe operária dos setores privados modernos, aqueles setores potencialmente decisivos do movimento operário.

Além disso, essa prática, em seu conjunto, teria resultado na dependência do movimento sindical em relação ao Estado e no distanciamento das bases. Esse último aspecto apresentava os limites fundamentais da orientação stalinista, que não priorizava as "organizações das bases operárias nas empresas, único fundamento sólido de qualquer perspectiva de reorganização do conjunto do movimento operário em um sentido democrático e independente" (Weffort, 1978a, p. 3).

Um dos principais pontos realçados na análise acima é o pouco empenho dos comunistas na alteração da estrutura sindical então vigente. Assim, seja nas origens do "sindicalismo populista" (1945-46), seja em seu período de amadurecimento e configuração final (1955-64), os comunistas teriam dado vida à estrutura sindical corporativa, sem apresentar qualquer caminho para sua superação. Um exemplo disso, ainda de acordo com Weffort, seria o seu reduzido empenho no combate ao imposto sindical, elemento essencial à manutenção e reprodução da referida estrutura.

Apesar das tentativas de se fazer ressalvas à posição de Weffort, empreendidas por autores ligados ou não às forças políticas em disputa (ver Troyano, 1978; Maranhão, 1979; e Delgado, 1986), as formulações que buscaram ler o passado alternativamente não avançaram muito, assumindo posi- ção subalterna no campo analítico. Assim como na política, onde o "novo sindicalismo", a CUT e o PT iam ocupando cada vez mais espaços e se transformando em forças hegemônicas frente a um PCB que ia perdendo cada vez mais terreno, no mundo das análises, a interpretação de Weffort (1973; 1978a) tornou-se a leitura hegemônica acerca do passado, preparando o terreno para as futuras investigações que encontravam, na crítica às práticas presentes e pretéritas do PCB, seu terreno familiar.

\section{AFABRICAÇÃO DA IDENTIDADE: a sociolo- gia pública e o "novo sindicalismo"}

A importância e a centralidade assumidas pelas formulações do autor podem ser constatadas pelas diversas pesquisas que as utilizaram. Mesmo nos estudos posteriores que buscaram a sua relativização, as ideias de Weffort continuaram servindo como um contraponto analítico muito frequente. Observando o discurso dos novos sindicalistas, vamos perceber que eles também tinham uma postura bastante crítica acerca do passado. Tomemos como exemplo sua visão sobre a prática do sindicalismo antes de 1964, no que diz respeito à sua lógica de ação, em geral, e à sua posição sobre a estrutura sindical, em particular.

Segundo Luiz Inácio Lula da Silva, então presidente do Sindicato dos Metalúrgicos de São Bernardo do Campo:

... teríamos de fazer uma certa divisão do movimento sindical (entre) antes e após 64. [...] Eu acredito que o movimento sindical antes de 64 foi muito usado politicamente, fazia-se talvez uma 'politicalha', em vez de defender realmente a categoria (NAP.PT-SP, 1981, p. 28).

Ainda segundo Lula,

... o sindicalismo pré-1964 não teria sido autônomo e independente, porque muitos movimentos eram feitos por interesses políticos, muitas vezes em benefício de quem estava no poder e mesmo de quem não estava, mas queria chegar lá (Lula da Silva, 1978, p. 54).

Por sua vez, José Ibrahim, um dos líderes da greve de Osasco de 1968 e um dos principais repre- 
sentantes do pensamento das Oposições Sindicais em fins dos anos 1970, considerava que as tentativas de ruptura com a estrutura sindical no período pré-1964 não seguiram passos corretos, isto é, a orientação assumida nesse sentido não teria sido a política “... mais consequente de romper com essa estrutura sindical. Porque ela estava sendo feita de cima, e o rompimento tem de começar de baixo." (1980, p. 69). Para Olívio Dutra, então um expoente da nova visão sindical no setor bancário, o “... novo sindicalismo" não podia reproduzir os erros do passado, criando organismos que não tinham maior vinculação com a base” (1984, p. 144).

Efetivando a ligação entre a luta que travava no presente contra o "peleguismo” e as questões do passado, Lula chegou a dizer que:

Os homens que estão todos aí, toda a cúpula do sindicalismo é composta por homens de antes de 64. Isso também define o pelego: o cara consegue se moldar a qualquer tipo de governo. [...] Não vivi bem a época do João Goulart, mas acho que ele ouvia muito dirigente sindical de gabinete, sem base popular (NAP.PT-SP, 1981, p. 29).

Sinteticamente, o sindicalismo do passado era visto pelos "novos sindicalistas" como sem bases, de cúpula, de gabinete, distante da classe trabalhadora e orientado por interesses políticos. Essa visão marcou algumas das concepções que informaram inicialmente as práticas do "novo sindicalismo", nas quais as representações negativas acerca do passado eram presença constante, indicando as práticas a serem ultrapassadas no presente. A negação radical do passado, ou da imagem que se tinha dele, serviu de apoio na busca por uma ruptura entre o "novo" e o "velho". Mas essa não foi sua única base de sustentação. Esse processo recebeu o reforço de análises que viam, na conjuntura pós-1964, fortes indícios de distinções e rupturas. Em certos casos, os estudos acabavam por apresentar um misto de análise acadêmica e programa de ação, apontando, a partir do contraste entre o "novo" e o "velho", qual deveria ser a orientação no campo sindical. ${ }^{9}$

${ }^{9}$ No que se refere às práticas sindicais, Weffort (1972) assinala as distinções entre as greves de Contagem e Osasco de 1968, organizadas pela base e por empresa, e os movimentos do sindicalismo "cupulista" do período 1945-64.
Sinteticamente, a emergência da nova classe operária produziu alterações no campo sindical que explicitaram as limitações da estrutura sindical corporativa, a qual tenderia, com isso, a ser empurrada para a mudança. Assim, se, no passado, o movimento sindical pôde se acomodar - ou ser acomodado... - à estrutura oficial, nesse novo contexto pareciam ser poucas as chances de acomodação ao modelo vigente. Essa nova conformação da classe repercutiu também no espaço político, ainda que, em um primeiro momento, de forma indireta.

Tanto quanto os estudos acadêmicos, os atores mais diretamente envolvidos no movimento social também pareciam se empenhar em marcar as diferenças desse "novo sindicalismo" em relação à trajetória histórica do movimento dos trabalhadores e em ressaltar que estavam construindo uma trajetória alternativa. A ideia do "novo”, em termos da composição da classe trabalhadora e da sua orientação política, é um ponto central no discurso do sindicalista Lula, conforme podemos observar nessa entrevista concedida em 1979:

O que está existindo lá no ABC, principalmente em São Bernardo, é uma massa jovem de trabalhadores, pessoas que não aceitam esse tipo de exploração, que querem participar da vida política do país, que não viveram o populismo de Getúlio Vargas (NAP.PT-SP, 1981, 179).

Um dos argumentos mais utilizados pelos "novos sindicalistas" para se distinguirem das lideranças do passado era a sua posição crítica diante da estrutura sindical corporativa brasileira, vista como um entrave imposto ao movimento dos trabalhadores. Segundo Lula, o movimento sindical teria esse "cordão umbilical preso ao Ministério do Trabalho" (NAP.PT-SP, 1981, p. 66). A estrutura sindical brasileira, construída de cima para baixo, seria, no seu entender, totalmente inadequada, cabendo aos trabalhadores "acabar com a contribuição sindical que atrela o sindicato ao Es-

Segundo sua análise, que subestima e desprestigia o papel da ação do sindicato oficial naqueles movimentos poderíamos reconhecer, na experiência das greves de 1968 as características de uma futura organização sindical independente e autônoma. 
tado. "O sindicato ideal é aquele que surge espontaneamente, que existe porque o trabalhador exige que ele exista" (idem, p. 45).

Esses argumentos servem para explicitar alguns dos pilares do "novo sindicalismo": a crítica radical aos mecanismos de tutela do sindicato pelo Estado e a luta pela liberdade e pela autonomia sindicais. Autonomia não só em relação ao Estado, mas também em face dos partidos políticos, evitando-se, assim, desviar o movimento dos interesses imediatos dos trabalhadores. Para Lula, esse seria um ponto de distinção entre o "novo" e o "velho" sindicalismo. No seu entender, o que havia mudado no sindicalismo brasileiro era o fato de que alguns dirigentes sindicais buscavam tornar o sindicalismo independente "de uma vez por todas".

As visões expostas até aqui, cunhadas na confluência entre os estudos sociológicos e a dinâmica do movimento sindical, cumpriram um papel destacado no contexto de fabricação da identidade do "novo sindicalismo". Tais concepções atingiram grande importância em meio à luta travada no campo político - que ampliou suas dimensões e seus impactos -, coroando o caráter público e orgânico dessa sociologia do trabalho que se renovou conjuntamente com o movimento sindical brasileiro nas décadas de 1970 e 1980.

\section{UMA SOCIOLOGIA PARA AS POLÍTICAS PÚBLICAS?}

Batizada pelos economistas brasileiros de "a década perdida", os anos 1980 terminaram imersos em uma profunda recessão econômica, associada a uma clara guinada política: pela primeira vez na história brasileira, um candidato de origem operária e dirigente emblemático do "novo sindicalismo”, Luiz Inácio Lula da Silva, disputa com chances reais de vitória a presidência da República. A derrota eleitoral nas eleições de 1989 para Fernando Collor de Mello, contudo, traduziu-se em um duro golpe para as pretensões hegemônicas do PT e da CUT, além de expressar uma flagrante derrota daquele projeto político for- jado nas décadas de 1970 e 1980, genericamente "socialista" e caracterizado pelas noções de "alternativa dos trabalhadores" e "independência política de classe".

No terreno da economia, por sua vez, a década de 1990 nasceu em meio a uma grande recessão que atingiu fortemente o conjunto da estrutura produtiva brasileira-em especial, os setores operários tradicionais -, inaugurando um período marcado pela diminuição dos postos de trabalho, pela redução do número de empregos formais, pela modificação do meio ambiente empresarial na direção das políticas de subcontratação, terceirização e flexibilização das relações de trabalho...

Tomados de surpresa, segmentos importantes do movimento sindical brasileiro procuraram fazer frente ao que se passava por meio da participação no processo de "modernização conservadora" dirigido pelas empresas. A experiência das "Câmaras Setoriais" e o chamado "Acordo das Montadoras" tornaram-se os grandes divisores de águas para o movimento sindical brasileiro herdeiro do "novo sindicalismo", assim como configurou um grande desafio para os sociólogos, especialmente, aqueles vinculados ao PT e à CUT.

De fato, nos primeiros anos da década de 1990, ocorreu um acalorado debate no interior do movimento sindical brasileiro - e que contou com a participação de diversos sociólogos - sobre a experiência das "Câmaras Setoriais" (Cardoso e Comin, 1993; Diniz, 1993; Arbix, 1995; Oliveira e Comin, 1999). As "Câmaras Setoriais" constituíram uma proposta de "modernização" do setor automobilístico brasileiro, organizada em torno de negociações que envolveram as empresas, o Estado e os sindicatos dos trabalhadores. ${ }^{10}$

Nesse modelo, as empresas se disporiam a garantir os empregos dos operários por um determinado período e a ampliar a capacidade produtiva do setor, o Estado se comprometeria a diminuir a carga tributária para estimular o consumo de carros, e os trabalhadores aceitariam moderar suas

${ }^{10}$ Posteriormente, o modelo foi expandido para outros setores da indústria nacional, sem, contudo, obter a mesma repercussão e adesão por parte dos trabalhadores (ver Mello e Silva, 1999). 
reivindicações em troca da manutenção do nível de emprego e da correção dos salários - que passou a ser feita mensalmente pela média das variações dos índices do mês anterior. O contexto de montagem desse arranjo institucional, num país sem tradição de negociações tripartites, explica, em boa medida, a atenção que as "Câmaras Setoriais" mereceram por parte dos movimentos sociais, de intelectuais acadêmicos e da grande imprensa.

A essência da proposta - que foi bastante debatida na época, no interior tanto do PT quanto da CUT - apontava para o estabelecimento de mecanismos tripartites de negociação de preços, salários e tributos, ao longo de toda a cadeia produtiva, objetivando a criação de uma espécie de "Fórum Nacional de Negociações", com a participação de entidades nacionais de trabalhadores e empresários, incluindo representantes do Congresso Nacional e de entidades da sociedade civil (Singer, 1994).

Em 1994, quando o debate sobre o tema foi retomado no interior do PT, por ocasião da campanha presidencial de Lula, chegou-se a uma espécie de consenso em torno desses mecanismos tripartites de negociação: nos termos aprovados no $9^{\circ}$ Encontro Nacional do PT, as "Câmaras Setoriais" correspondiam a um importante instrumento de "democratização da vida econômica", podendo "contribuir para o controle social sobre os oligopólios" e "assumir um papel fundamental na implementação da política industrial". ${ }^{11}$

Independentemente das polêmicas em torno da avaliação dos resultados das "Câmaras Setoriais", ${ }^{2}$ cabe realçar que, com esse debate, o movimento sindical brasileiro logrou construir, a partir de instituições não-acadêmicas - notadamente, o Dieese (Departamento Sindical de Estatísticas e Estudos Sócio-Econômicos) e o Desep (Departamento de Estudos Sociais, Econômicos e Políticos da CUT) - ,

${ }^{11}$ Ver, para mais detalhes, Diretório Nacional do PT (1998).

${ }^{12}$ De fato, para as montadoras o acordo foi muito vantajoso, aumentando as vendas. Já o número de empregos no setor caiu. No tocante aos salários, dados do DIEESE demonstram que os níveis salariais foram estabilizados, sem haver, todavia, nenhuma recuperação das perdas sofridas
anteriormente (ver dados citados por Anderson, 1997). um discurso analítico capaz de interagir com a sociologia profissional acadêmica em condições de relativa "igualdade". Naturalmente, a participação de "assessores sindicais", muitos deles sociólogos e economistas, tanto no Dieese quanto no Deseptodos muito familiarizados com a "linguagem acadêmica”, os métodos e as técnicas da pesquisa profissional-foi de fundamental importância para que essa situação de relativa "igualdade" entre o movimento sindical e a sociologia profissional pudesse se tornar viável. ${ }^{13}$

Por mais que existam polêmicas em torno das razões capazes de explicar as recentes transformações do movimento sindical brasileiro, é incontestável que a transição da década de 1980 para os anos 1990 foi marcada pela substituição de um estilo de ação sindical baseado na centralidade do conflito por outro estilo que claramente privilegia as práticas de negociação, ou, ao menos, como indicou Rodrigues (1995), de "cooperação conflitiva”. A relação de grande parte da sociologia do trabalho com o sindicalismo, nesse período, evoluiu em relativa harmonia com os novos tempos. Por tudo que representou e pelo momento histórico no interior do qual se desenvolveu, o debate sobre as "Câmaras Setoriais" encerrou um ciclo dessa relação, ao mesmo tempo em que inaugurou outro.

Por um lado, aquele vínculo solidário entre acadêmicos e lideranças sindicais - marcado pelo caráter crítico, militante e interdependente de um diálogo que chegou a forjar certo consenso em torno do lugar e das tarefas históricas do "novo sindicalismo" brasileiro - foi esgarçado e superado. O próprio lócus do diálogo mudou: da academia para as instituições de pesquisa construídas pelo movimento sindical. Na verdade, o debate sobre as "Câmaras Setoriais" pode ter representado o começo de uma renovada "instrumentalização" da sociologia do trabalho, cujo sentido apontava inelutavelmente para a formulação de políticas públicas.

${ }^{13}$ A consolidação e desenvolvimento desses corpos "técnicos" por dentro ou vinculados às estruturas sindicais fez com que mesmo as Organizações Não-Governamentais, que, em fins dos anos 1970 e durante os anos 1980 , auxiliaram o sindicalismo com seus "assessores", diminuíssem muito seu grau de inserção e ação. 
Nesses termos, é digna de nota a recente incorporação direta de acadêmicos aos órgãos do governo, especialmente ao Ministério do Trabalho e Emprego (MTE), com a eleição de Lula e que passaram à formulação imediata e ao debate de tais políticas.

\section{CONSIDERAÇÕES FINAIS}

A análise da relação entre a sociologia do trabalho e o sindicalismo no Brasil deixa claro que ela experimenta um movimento quase pendular: da crítica teórico-metodológica ao engajamento social dos estudos sobre o trabalho da década de 1950, a sociologia do trabalho brasileira emerge, nos anos 1960, marcada por um primeiro ciclo de profissionalização. Da renovação das lutas sociais acompanhadas por uma nova onda de engajamento social, presente nas décadas de 1970 e de 1980, passamos para um novo ciclo de profissionalização nas décadas de 1990 e 2000. Uma profissionalização que tem em comum com aqueles trabalhos pioneiros da década de 1960 o cuidado com os métodos e as técnicas de pesquisa, assim como com a valorização instrumental do conhecimento sociológico. Entretanto, as coincidências acabam quando pensamos nos diferentes tipos de audiência do discurso sociológico.

Se, na década de 1960, os primeiros sociólogos do trabalho lutaram simbolicamente por formar um campo singular e uma audiência acadêmica para acolher a sociologia do trabalho nascente, diferenciando-a daquele tipo de conhecimento políticoprogramático acerca da classe trabalhadora, de ascendência stalinista, a partir dos anos 1990, a direção muda no sentido de uma audiência cada vez mais extra-acadêmica cujos interesses gravitam em torno das políticas públicas e, consequentemente, do poder de Estado. A vitória eleitoral de Luiz Inácio Lula da Silva, em 2002, parece ter coroado esse novo ciclo de profissionalização, com a entrega do Ministério do Trabalho brasileiro para o controle da CUT e, posteriormente, da Força Sindical. A sociologia pública terá sido definitivamente substituída por uma sociologia para as políticas públi- cas no Brasil? Ou estaria o pêndulo dos estilos sociológicos prestes a oscilar novamente, inaugurando um novo período?

(Recebido para publicação em abril de 2009) (Aceito em julho de 2009

\section{REFERÊNCIAS}

ANDERSON, P. A política industrial no Brasil e a experiência das câmaras setoriais na década de 90. 1997. (Dissertação de Mestrado). Porto Alegre: UFRGS.

ARBIX, G. A. T. Uma aposta no futuro: os três primeiros anos da câmara setorial da indústria automobilística e a emergência do meso-corporatismo no Brasil. 1995. (Tese de Doutoramento). São Paulo: Universidade de São Paulo.

BIANCHI, Alvaro. Gramsci e as ciências sociais. Revista de Sociologia e Política, n. 29, p. 7-14, nov. 2007.

BRAGA, R.; SANTANA, M. A. Brazil the swinging pendulum between labor sociology and labor movement. Work and occupations, Londres: Sage, v. 36, n. 2, p. 96109, 2009.

BRITO, José Carlos. A tomada da Ford. Petrópolis: Vozes, 1989.

BURAWOY, Michael. For public sociology. American Sociological Review. v. 70, p. 4-28, 2005.

CABANES, Robert. Travail, famille, mondialisation: récits de la vie ouvrière, São Paulo, Brésil. Paris: IRD/Karthala, 2002.

CARDOSO, Adalberto, COMIN, Álvaro. Câmaras setoriais, modernização produtiva e democratização nas relacões de trabalho no Brasil: a experiência do setor automobilístico. In: CASTRO, Nadya Araújo (Org.) A máquina e o equilibrista: inovações na indústria automobilística brasileira. Rio de Janeiro: Paz e Terra, 1993.

DELGADO, L. Neves. O Comando Geral dos Trabalhadores no Brasil: 1961/1964. Petrópolis: Vozes, 1986.

DESEP. Câmaras setoriais e intervenção sindical. São Paulo: Desep/CUT, (Texto para Discussão, 5), 1992.

DINIZ, E. Articulação dos atores na implementação da política industrial: a experiência das câmaras setoriais retrocesso ou avanço na transição para um novo modelo? Estudo da competitividade da indústria brasileira. Campinas, (Nota Técnica Extra-Blocos Temáticos), 1993.

DIRETÓRIO NACIONAL DO PT. Resoluções de Encontros e Congressos: Partido dos Trabalhadores (1979-1998). São Paulo: Perseu Abramo, 1998.

DUTRA, Olívio. Entrevista. Revista Escrita/Ensaio. São Paulo, n. 13, 1984.

FERREIRA, Jorge (Org.). O populismo e sua história. Debate e crítica. Rio de Janeiro: Civilização Brasileira, 2001.

GRACIOLLI, Edilson. Um caldeirão chamado CSN: resistência operária e violência militar na greve em 1988. Uberlândia: Edufu, 1997.

GUIMARÃES, Nadya Araujo. Caminhos cruzados: estratégias de empresas e trajetórias de trabalhadores. São Paulo: Editora 34, 2004. 
IANNI, Octávio. O colapso do populismo no Brasil. Rio de Janeiro: Civilização Brasileira, 1978.

IBRAHIM, José. Entrevista. Revista Escrita/Ensaio. São Paulo, n. 6, 1980

LE VEN, Michel. Processo de trabalho e classe trabalhadora. Comunicação apresentada ao VII ENCONTRO ANUAL DA ANPOCS, São Paulo, 1983.

LOBO, Elizabeth Souza; SOARES, Vera. Masculino e feminino na linha de montagem. Comunicação apresentada ao IX ENCONTRO ANUAL DA ANPOÇS, São Paulo, 1985.

LOPES, Juarez Brandão. Sociedade industrial no Brasil. São Paulo: Difusão Europeia do Livro, 1964.

Crise do Brasil arcaico. São Paulo: Difusão Europeia do Livro, 1967.

LULA DA SILVA, Luiz Inácio. Entrevista. Revista Cara a Cara. Campinas: Centro de Estudos Everardo Dias, n. 2, 1978.

MARANHÃO, R. Sindicatos e redemocratização. São Paulo: Brasiliense, 1979.

MATTOS, Marcelo B. E. P. Thompson no Brasil. Outubro, São Paulo: Alameda, n. 14, p. 38-51, 2006.

MELLO E SILVA, Leonardo . A generalização difícil: a vida breve da câmara setorial do complexo químico seguida do estudo de seus impactos em duas empresas do ramo. São Paulo: Annablume, 1999.

MIGLIOLI, Jorge. Como são feitas as greves no Brasil. Cadernos do Povo. Rio de Janeiro: Civilização Brasileira, n. 13,1963

NORONHA, Eduardo. Greves na Transição Brasileira. 1992 Dissertação (Ciência Política). Programa de Pós-Graduação em Ciência Política, Unicamp. Campinas.

NÚCLEO AMPLIADO DE PROFESSORES DO PT/SP - NAP. Lula: entrevistas e discursos. São Paulo: O Repórter, 1981.

OLIVEIRA, Dante; LEONELLI, Domingos. Diretas Já: 15 meses que abalaram a Ditadura. São Paulo: Record, 2004.

OLIVEIRA, Francisco de; COMIN, Álvaro. Os cavaleiros do antiapocalipse: trabalho e política na indústria automobilística. São Paulo: Cebrap/Entrelinhas, 1999.
RODRIGUES, Leôncio Martins. Apresentação. In: LOPES Juarez Brandão. A crise do Brasil arcaico. São Paulo: Difusão Europeia do Livro, 1967.

Industrialização e atitudes operárias: estudo de um grupo de trabalhadores. São Paulo: Brasiliense, 1970

RODRIGUES, Iram J. O sindicalismo brasileiro: da confrontação à cooperação conflitiva. São Paulo em Perspectiva, v. 9, n. 3, São Paulo: Fundação SEADE, 1995.

RODRIGUES, José Albertino. Sindicato e desenvolvimento no Brasil. São Paulo: Difusão Europeia do Livro, 1968.

SADER, Sader; PAOLI, Maria Célia. Sobre as classes populares no pensamento sociológico brasileiro”. In: CARDOSO, Ruth (Org.) Aventura antropológica. Rio de Janeiro: Paz e Terra, 1986

SIMÃO, Aziz. O sindicato e o Estado: suas relações na formação do proletariado de São Paulo. São Paulo: Dominus, 1966.

SINGER, Paul. A batalha decisiva. Teoria de Debate. São Paulo: Fundação Perseu Abramo, n. 25, p. 30-35, 1994.

TROYANO, A. Estado e sindicalismo. São Paulo: Símbolo, 1978.

VIANNA, Luiz Werneck. Travessia - da abertura à constituinte 86. Rio de janeiro: Taurus. 1986.

WEFFORT, Francisco. Participação e conflito industrial: Contagem e Osasco 1968. Cadernos Cebrap. São Paulo: Cebrap, n. 5, 1972.

Origens do sindicalismo populista no Brasil (A conjuntura do após-guerra). Estudos Cebrap, São Paulo, n. 4, p. 27-43, 1973 .

Entrevista aos Cadernos de Debate. História do Brasil. São Paulo: Brasiliense, n. 1, p. 82, 1976.

Os sindicatos na política (Brasil: 1955-1964). Ensaios de Opinião. Rio de Janeiro: Enubia, n. 1, 1978a.

Democracia e movimento operário: algumas questões para a história do período 1945/1964. Revista de Cultura Contemporânea. São Paulo, n. 1, 1978 b. 


\section{THE ROCKING PENDULUM - sociology of labor and union's movement in Brazil}

\section{Marco Aurélio Santana Ruy Braga}

The present paper analyzes the relationship established between sociology of labor and the unionism in Brazil. That is done by covering three moments of that relationship. Having as a backdrop the successive political and economical conjunctures, we go from that first generation of work sociologists to the recent period, trying to identify the most characteristic points in that trajectory. We work with the hypothesis according to which, along its trajectory, sociology of labor in Brazil was marked, in its origins, by the search for affirmation and professionalism (1950/1960); later, it developed a strong political and social engagement, assuming a public character and serving to conform to certain social identities (1970/ 1980); finally, it would have turned into a sociology for public policies (1990/2000).

KEYwORDS: sociology of labor, social identities, workers, unionism.

\section{PENDULE OSCILLANT - la sociologie du travail et l'action des syndicats au Brésil}

\author{
Marco Aurélio Santana \\ RuyBraga
}

Ce travail consiste en l'analyse de la relation existante entre la sociologie du travail et le syndicalisme au Brésil. Pour ce faire, trois moments de cette relation ont été pris en considération. Nous avons comme toile de fond les diverses conjonctures politiques et économiques, et comme point de départ, la première génération de sociologues du travail jusqu'à une période récente, en essayant d'identifier les éléments les plus caractéristiques de cette trajectoire. Nous sommes partis de l'hypothèse que tout au long de sa trajectoire, la sociologie du travail a été marquée, au Brésil et à ses tous premiers débuts, par la recherche d'une affirmation et d'une professionnalisation (1950/1960); elle s'est ensuite développée dans le sens d'un engagement politique et social considérable en assumant un caractère public et en permettant de constituer certaines identités sociales (1970/1980); enfin, elle serait allée vers des politiques publiques (1990/2000).

MoTS-CLÉs: sociologie du travail, identités sociales, travailleurs, syndicalisme.

Marco Aurélio Santana - Doutor em Sociologia pela UFRJ. Professor do Departamento de Sociologia e Coordenador do Programa de Pós-Graduação em Sociologia e Antropologia da UFRJ. Desenvolve pesquisas na área de Sociologia do Trabalho, com ênfase em trabalhadores, sindicatos e ações coletivas. Publicou, entre outros: Homens partidos: comunistas e sindicatos no Brasil (São Paulo, Boitempo, 2001) e Sociologia do trabalho no mundo contemporâneo (em co-autoria com José Ricardo Ramalho, $2^{\text {a }}$ edição, Rio de Janeiro: Zahar ed., 2009).

Ruy Braga - Doutor em Ciências Sociais pela Unicamp. Professor do Departamento de Sociologia da USP. Diretor do Centro de Estudos dos Direitos da Cidadania (Cenedic - USP). Desenvolve pesquisas nas áreas de Sociologia do Trabalho e Teoria Sociológica. Sua mais recente publicação é o livro intitulado Infoproletários: Degradação real do trabalho virtual (em co-autoria com Ricardo Antunes). 